\section{Developmental Supervision for Nurses}

\section{Donnelly, G. Brooks, $P$.}

\begin{abstract}
Developmental supervision is gaining increasing recognition in nursing as a form of clinical supervision that will promote professional growth and ultimately lead to improved patient care. Benner's (1984) model of career development is used as a framework in which to examine appropriate forms of supervision for each developmental stage. Directive, collaborative and non-directive supervision are applied to each of these developmental levels.
\end{abstract}

\section{Introduction}

Clinical supervision has been described as a 'major' if not the major force in improving clinical standards and enhancing the quality of care. Supervision promotes personal and professional development in a supportive relationship and is fundamental to safeguarding standards, the development of professional expertise and the delivery of quality care (Butterworth \& Faugier, 1992). Nursing's need for clinical supervision has never been greater. The need to support nurses in uncertain times, increase morale and decrease conflict, resolve personal and interpersonal difficulties, ensure less strain and burnout and encourage self-awareness and self-expression has arisen in a changed nursing context of valuing relationships with patients (Garbettt, 1995).

The common understanding of supervision within the nursing profession is that of administrative supervision. Administrative supervision is a bureaucratized hierarchal supervision primarily concerned with overseeing activities. It means that supervisors manipulate subordinates behavior to reach the goals of the organization through the use of administrative principles (Hand, 1981). These principles typically include planning, organizing, controlling and evaluating (Singleton, 1998). The trend to apply business administration models to the management of health care has entrenched this notion of supervision. Furthermore, clinical supervision has been relegated to psychotherapy focusing on developing therapeutic skills (Wolsey \& Leach, 1997).

Developmental supervision has been used in the educational system for some time and is described by Glickman, Gordon \& Ross-Gordon (1998). It is based on the premise that human development is the goal of education. Therefore supervision should be eclectic in practice, directed toward the goal of a nondirective supervision in which the supervisor provides an environment that enables the teacher to explore his or her own physical and mental capabilities. The goal of supervisors is to return control to the teaching faculty to decide on collective, instructional improvements. These authors go on to say that supervisors can use a variety of practices that emanate from various philosophies and belief structures with developmental directionality in mind. Directive, collaborative and nondirective supervisory approaches are all valid as long as they aim to increase teacher self-control. Supervision encompasses actions that enable teachers to improve instruction for students.

The principles inherent in Glickman, Gordon \& RossGordon's (1998) description of supervision are equally applicable to nursing practice. There is an increasing amount of evidence to show that there are benefits to implementing supervision. It has been claimed that supervision, if implemented effectively, will bring benefits as diverse as improved patient care through increased skills and knowledge (Butcher, 1995), a reduction in stress levels (Butterworth, Carson, \& White, 1997), a reduction in complaints and an increase in staff morale (Butterworth, Carson, \& White, 1997). Other reported benefits include increased knowledge and awareness of possible solutions to clinical problems (Dudley \& Butterworth, 1994), increased confidence and reduced emotional strain and burnout (Hallberg $\&$ Norberg, 1993), increased participation in reflective practice (Hawkins \& Shohet, 1989) and increased self-awareness (Cutcliffe, Epling, \& Cassedy 1998). Clinical supervision in nursing is gaining rapid acceptance as a mechanism that promotes safe and effective practice, maintains standards and accountability, and develops nursing practilioner's autonomy (Yegdich, 1999). The benefits identified have implications not just for nurses but also patient care and employers of nurses.

\section{Stages of Development \& Implications for Supervision}

Benner's (1984) classic work based on the study of theoretical and practical knowledge in nursing practice identified stages of career development based on the Dreyfus model (Dreyfus \& Dreyfus, 1980) of skill acquisition. According to the model, the nurse passes through five stages of career development; novice, advanced beginner, competent, proficient and expert. Skill attainment requires an ordinal progression through these stages and discrete capabilities reflect the stage of development reached. This incremental development is dependent on a combination of depth and range of clinical experience, which is positively correlated with the length of time spent nursing.

It is reasonable to infer that theoretically, over time and with all the necessary experience, all practitioners could eventually become experts and perform at the various stages, but experience is not the mere passage of time or longevity; it is the refinement of preconceived notions and theory by encountering many actual practical situations that add nuances or shades of difference to theory (Benner, 1982). 
Through this process nurses develop and refine clinical knowledge.

The assumption that nurses are fully ready to practice by the time they finish nursing education probably reflects the difficulty within the culture and the discipline in recognizing expertise acquired through experience in practice. The reluctance to admit that nurses don't graduate as fully skilled professionals, but rather as novices and advanced beginners who require many years of experience to fill out their skills and become expert, also upholds a myth which is accepted in many health care institutions that nurses of any skill or educational level are roughly equal in their abilities to fulfill staffing needs (Benner, Tanner, \& Chesla, 1996). Developmental supervision fosters the development of skill and attributes essential for nurses to move toward mature responsible practice (Canham, 1998).

Glickman, Gordon and Ross-Gordon( 1999) have constructed a developmental supervision model. In this model they stress that the ultimate supervisory approach is a nondirective method, however, it is essential for the supervisor to consider the level of development, expertise, confidence and commitment of the individual being supervised. Supervisory behaviors are aimed at promoting and accommodating long range development toward higher levels of reflection and problem solving ability. This model identifies three approaches used by supervisors. The nondirective technique has the supervisor rely primarily on listening, clarifying and reflecting behaviours. In the collaborative method, the leader performs more presenting, problem solving and negotiating functions. Thirdly, the directive approach emphasizes directing and standardizing behaviours. This third approach is further extended to the directive informational and directive control approaches. The directive control strategy has a supervisor determine the specific actions that are to be followed, whereas the supervisor exhibiting the directive informational approach will provide considerable information and then, restricted choice.

\section{The Novice Stage}

The beginner has no experience of the situations in which he or she is expected to perform. To give beginners entry to these situations and to allow them experience in developing skills, they are taught about situations in terms of objective attributes. Novices are taught context free rules to guide action with respect to different attributes. The rulegoverned behavior typical of the novice is extremely limited and inflexible (Benner, 1984). Through instruction, the novice acquires rules for drawing conclusions or for determining actions based upon facts and features of the situation that are recognizable without experience in the skill domain being learned. The knowledge imparted to the novice is theoretical knowledge, yet for application there may be no theoretical description. This points to the superiority of combining theory and experience taught applications (Berner, Tanner, \& Chesla, 1996).
Novice nurses, like novice teachers are functioning at a low developmental and expertise level, because they lack experience. Novice nurses are equipped with the theory and limited supervised clinical experience but need the opportunity to put these into practice. Glickman et al., (1998) suggests that a directive supervision approach is useful when teachers have little expertise, and found that beginning teachers preferred a directive supervisory approach. Gordon (1991) suggests that a direct information strategy best meets the supervisory needs of the novice teacher Houk (1999) supports a developmental supervision model for the novice teacher as it is designed to improve the beginning teacher, it is not to decide if the novice is a capable teacher. The novice nurse, like the novice teacher benefits from a directive supervisory approach, which may be either a direct control or informational approach. This type of approach requires that the supervisor make explicit guidelines and principles that will allow the novice entry into the clinical practice in a safe and efficient way (Benner, 1984).

The supervision method of mentoring has been used in nursing and benefits the new graduate in that the mentor can be a role model who actively teaches, coaches, develops and critiques novice nurses by guiding and facilitating professional growth (Rocchiccioli \& Tilbury, 1998). In choosing a mentoring approach for supervision, the mentor must have clinical expertise, knowledge, experience, a desire to nurture and an emotional commitment to his or her profession (Darling, 1985).

\section{The Advanced Beginner Stage}

The advanced beginner can demonstrate marginally acceptable performance and has coped with enough real life situations to note or to have pointed out by a mentor the recurring meaning ful aspects of a situation (Benner, 1984). Clinical situations present to advanced beginners as opportunities for learning from practical realities, particularly in relation to their theoretical training. In a similar vein clinical realities appear to be somewhat ordered, requiring the appropriate application of appropriate knowledge. Another prominent aspect of the advanced beginners' clinical world is that the situations shows up as a test of his or her personal capabilities. Advanced beginners care for patients in ways that are largely guided by factors that are external to the inmediate patient care situation. Standards of care and unit procedures, as well as physicians' and nurses' orders, provide this external guidance. They demonstrate extraordinary dependence on the expertise of others, a striving to assert their own independent practice, and a continual questions about their capacity to contribute. (Benner, Tanner \& Chelsa, 1988).

Mentors are experienced nurses who serve as role models. Beginners acquire or modify behaviors by observing vicariously a model who has the behaviors needed by the learner and then have the opportunity to practice those behaviors. The mentor provides instruction for learners based 
on identified beginners' learning needs, assists beginners in integrating education and work values. By working on a one- to- one basis with a nurse who is functioning in this role, beginners are able to model behaviors of the nurse and become socialized into a professional role. This also provides an opportunity for a mentoring relationship with the beginner which is important for facilitating role transition (Reilly \& Oermann, 1990). The mentor guides the beginner in gaining the knowledge and skills needed for care of clients and learning about the role and responsibilities of the nurse in that setting (Bizek \& Oermann, 1990). This one- to- one relationship between the mentor and learner provides for close supervision and inmediate feedback on performance; beginners develop competence in performing clinical skills and increase self-confidence in their new role (Oermann, 1990).

Advanced beginners' unique ways of being involved in their clinical world and their particular form of clinical agency call for mentorship as a teaching strategy. Since advanced beginners live in clinical worlds where the patient situations shows up as elemental, partial and dominated by tasks and procedures, mentors can help beginners fit the seemingly disjointed components of report, chart, and physical presentation of the patient into a meaningful whole. By working through this process with particular patients, beginners can begin to see patterns and glimpses of the whole patient's condition. Drawing on the experience of the mentor, beginners can start to find order in the immense amount of information that they are given on each patient moment by moment. Mentors can also provide for beginners the historical context and possible future course of a patient situation. Beginners simply haven't had time to see patients with varied disease processes through complete illness trajectories. Lacking this experience, beginners can't place into perspective new symptoms or patient responses. When new symptoms arise, beginners may focus excessive attention or worry on them, rather than recognize them as an expected pattern of recovery. Mentors can readily contextualize a symptom for advanced beginners and let them know what is and is not to be expected with particular illness and patients. This teaching cannot replace first hand experience, but allows beginners to have a broader focus and to recognize patterns of recovery when they actually come up. In their efforts to match patient conditions with past theoretical learning, mentors can validate the beginner's observations of new and unfamiliar conditions, encourage further explorations, and present some of the variations in the conditions that they should be watching for. Beginners leam from mentors how to weigh and balance competing concerns and attend to the most important concerns in concrete experience with many patients they encounter together (Benner, Tanner \& Chesla, 1996).

Administrators and managers of nursing departments should consider sharing supervisory responsibilitics through the use of mentors for advanced beginners. Crain and Young (1990) stress the involvement of "peer supervisors" who work in conjunction with the administrator. The mentor functions as a role model and provides individualized clinical instruction, support and socialization for the beginner (Stokes, 1998). Mentors who serve as peer supervisors may use a range of techniques including direct control and direct information to guide advanced beginners. When the nurse does not have the experience or awareness to act on an issue, or when an emergency arises, the mentor can take more direct control of the situation by directing the beginning nurse. In situations where the outcome is not as critical, the mentor may use a direct informational approach that allows the beginner to have input and choose alternatives and solutions (Glickman, Gordon. \& Ross- Gordon, 1998). Haipt (1990) argues for the use of colleagues as mentors as this can increase the retention rates among new teachers. Bain (1996) found a similar phenomenon in her study of nursing literature on mentorship and preceptorship.

\section{The Competent Stage}

The advanced beginner moves to competence in part because a crisis in confidence but also as a result of being taught by actual clinical situations and the actions by other health care workers (Benner, Tanner, \& Chesla, !992). The competent level of nurse differs primarily from the advanced beginner by his or her increased clinical understanding, technical skill, organizational ability, and the ability to anticipate the likely course of events. The focus of the nurses' attention is now on clinical issues, such as the clinical condition and management of the patient and less on getting tasks organized and completed. At the competent stage the nurse has gained the ability to anticipate certain typical progressions in the patient's recovery and likewise begins to perceive discomfort when the patient's progression violates experientially gained expectations. The competent nurse is more discriminating about the perfornance of other members of the health care team, and the exposure to increasing divergence and complexity in patients ' responses creates a search for broader and more extensive explanations. Competent practitioners discover the nature of clinical and ethical knowledge as different from the application of science and technology (Benner, Tanner, \& Chesla, 1996).

As the competent nurse becomes more and more emotionally involved in his or her tasks it becomes increasingly difficult to draw back and to adopt the detached rule-following stance of the beginner. While it might seem that this involvement caused interference with detached rule testing and improving would inhibit further skill development, in fact, just the opposite seems to be the case. The replacement of the detached rule-following stance of the novice and advanced beginner by involvement, should it occur, sets the stage for further advancement, while resistance to the frightening acceptance of risk and responsibility can 
lead to stagnation and ultimately to boredom and regression or withdrawal (Benner, Tanner, \& Chesla, 1996).

During the competent stage there is clearly a time of evaluation and questioning for nurses about whether nursing meets their expectations and whether they feel that they measure up to the demands placed on them by nursing. Competent level nurses are better able to recognize their own shortcomings as well as the lack of clinical competency in others. In contrast, beginners could naively feel that others had more experiential wisdom and that their own shortcomings were to be expected as a new comer. Failure for the competent nurse is closely linked to failed expectations, unmet goals and disrupted planning in specific situations. More nurses at the competent level begin to look for other jobs or leave nursing altogether. This is a critical point for nurses in that they either adapt or reject the work life demands (Benner, Tanner, \& Chesla, 1996).

Studying the disillusionment and crises of the competent nurse presents an ethical, professional, societal and institutional challenge because the crises of the competent nurse reflects the crises inherent in the health care system and in nursing education and practice. Their concerns and learning demands present an agenda for institutional and societal reform (Benner, Tanner, \& Chesla, 1996).

The competent stage is a critical developmental step in becoming an expert nurse. It is a point where nurses may change positions or careers in order to solve the crises they experience relating to the limits of their ability to cope with increased organizational demands and struggling to keep things stable or in status quo. As the competent nurse is sensitive to the limits of technology and the impact of illness on patients as people, participating in more open collaborative discussions with health professionals and or ethicists about the limits of medical interventions is crucial. Listening carefully to their struggles rather than insisting that they "cope" or manage are essential for creating an atmosphere that can reverse the disillusionment. Open discussions about learning skills of involvement with patients with highly effective nurses who have found ways to cope with the human needs of patients can be of great value. Telling and listening to narratives from practice that capture the best practice helps identify and extend innovations in practice. Narratives of breakdowns, conflict, and ethical dilemmas can be a source for correcting barriers to good practice (Benner, Tanner, \& Chesla, 1996).

The competent stage of nurse development lends itself to the collaborative type of supervision. It is premised on participation by equals in making decisions; its outcome is a mutually agreed upon plan of action. It is appropriate when supervisors and nurses have similar levels of expertise, involvement and concern with the problem. The supervisor facilitates a process of consensus, through the process of clarifying, understanding the nurse's perspective, verifying the perspective, presenting a point of view, prob- lem solving, encouraging disagreement and agreeing upon the details of the plan. The supervisor relies extensively on skills of negotiation (Glickman, Gordon, \& Ross-Gordon, 1998).

\section{The Proficient Stage}

Characteristically, the proficient nurse perceives situations as wholes rather than in terms of aspects, and performance is guided by maxims. Perception is paramount, as this perspective presents itself based on experience and recent events. Proficient nurses understand a situation as a whole because they perceive its meaning in terms of long-term goals. This experienced based ability to recognize whole situations allows a nurse at this stage of development to recognize when the expected normal picture does not materialize; this holistic understanding improves the proficient nurse's decision making. The proficient nurse, based on experience, considers fewer options and hones in on the accurate region of the problem (Benner, 1984). Proficiency seems to develop if and only if, experience is assimilated in a way in which theory based rules and principles are replaced by situations and discriminations accompanied by associated responses. Intuitive behavior replaces reasoned responses (Benner, Tanner, \& Chesla, 1996). Proficient nurses no longer feel anxious about the consequences of what they might leave out because they have more confidence in their ability to notice the important things (Benner, Tanner \& Chesla, 1992).

Proficiency is a transition stage because once the nurse begins to see changing relevance, it seems that seeing a clinical situation in terms of a past clinical situation, complete with all its sense of salience, is a next step in the skill of seeing. The crucial shift is the perceptual ability to read the situation and respond appropriately. Practice is transformed in six major ways: 1. The development of engaged reasoning in transitions. 2. Emotional attunement to the situation-doing what needs to be done. 3 . The ability to recognize changing relevance of aspects of the situation. 4. A socially skilled sense of agency. 5 . Improved and more differentiated skills of involvement with patients and families (Benner, Tanner, \& Chesla, 1996).

Similar to the competent stage of development, the proficient stage also calls for collaborative supervision strategies. Collaborative supervision is premised on participation by equals in making instructional decisions. Its outcome is a mutual plan of action. Collaboration is appropriate when individual nurses or groups of nurses and supervisors have similar levels of expertise, involvement, concern with the problen. The supervisor functions to facilitate common understandings of the problems and solutions through interactive processes of clarification, listening, presenting, encouraging, problem solving and negotiating (Glickman, Gordon \& Ross-Gordon, 1998). Application of collaborative supervision to the proficient stage of nurses, the use of 
clinical narratives which allow for mutual dialogue and sharing realistic concerns as they occur provides opportunity for shared reflection. Proficiency marks the transition between competency and expertise. Supervisory support at this stage can enhance the development of expertise. At this level, the organization, the discipline and the professional have much to learn from the practitioner. The practice of the proficient nurse should guide the design of the patient care delivery model as it has great potential to improve the quality of care and enhance his or her practice. Interprofressional dialogue between practitioners at this level helps to build clinical knowledge, promotes reflective practice and assists the proficient nurse to identify his or her own learning needs (Benner, Tanner, \& Chesla, 1996).

\section{The Expert Stage}

The expert nurse no longer relies on an analytical principle to connect her or his understanding of the situation to an appropriate action. The expert nurse with an enormous backgiound of experience has an intuitive grasp of each situation and zeros in on the accurate region of the problem without wasteful consideration of a large range of unfruifful, alternative diagnosis and solutions. Capturing the descriptions of expert performance is difficult, because the expert operates from a deep understanding of the situation (Benner, 1984). The expert nurse's practice also differs greatly in that the expert's direct access to action and his or her fluid skillful maneuvering in very complex in difficult situations. The expert is at home in managing rapidly changing situations and is able to attend to many of the aspects of care that go unnoticed by the less experienced clinician. The expert also has a sense of agency and responsibility for the patient's well-being and is more realistic in terms of actual possibilities inherent in the situation and in the nurses's capabilities (Benner, Tanner \& Chesla, 1992). The expert not only sees what needs to be achieved, but also knows how to achieve it. When things are proceeding normally, experts do not solve problems and do not make decisions; they simply do what experience has shown normally works (Benner, Tanner, \& Chesla, 1996).

The expert nurse apparently interprets clinical situations using a different set of constructs from the inexperienced nurse. This perceptual awareness is portrayed as intuitive and is strengthened by familiarity with the patient and the context. This intuition is the exclusive province of the expert but there are communication difficulties which limit the transference of information concerning clinical situations between the expert and the non-expert because the experts cannot explain how they makes their deductions (English, 1993; Benner, Tanner, \& Chesla, 1992).

Expert clinicians are not difficult to recognize because they frequently make clinical judgements or manage complex chinical situations in a truly remarkable way. But while recognition from colleagues and patients is apparent, expert performance may not be captured by the usual criteria for performance evaluations. It is at this juncture that the limits of formalism-that is, the inability to capture all the steps in the process of highly skilled human performance, become apparent. Expert nurses benefit from a nondirective supervision approach that allows for reflection on their own practice, engaged reasoning with other experts, and the development of knowledge.

Systematic documentation of expert clinical performance is the first step in clinical knowledge development, and expert clinicians can benefit from systemically recording and describing critical incidents from their practice that illustrate expertise or a breakdown in performance. As expert clinicians document their performance, new areas of clinical knowledge are made available for further study and development (Benner, 1984). The use of narratives assists expert nurses put description to their intuitive processes. Opportunities need to exist that allow them to develop a consensus about descriptive language about comparable observations among expert nurses which then enables them to further develop their performance. Expert nurses should have the opportunity to discuss their ethical dilemmas and the experience of discovering the unexpected in patient situations. By giving language to clinical expertise, expert clinicians can take more active roles in designing the organizational structure and processes for improved patient care. Once this happens, they have the tools by which they can serve in a consultative role to other nurses (Benner, 1984; Benner, Tanner, \& Chesla, 1996).

Continued development of expert clinical reasoning requires that practitioners develop and transmit their acquired skilled judgements and skilled ethical comportment to other practitioners. Peer coaching and evaluation can foster the development of clinical expertise as well as recognize and reward extant nursing expertise. As the health care systems continues to face downsizing and restructuring it is even more important to retain expert nurses. This is best accomplished through a peer review strategy of clinical supervision (Benner, Tanner, \& Chesla, 1996). Clinical supervision is a process that not only provides assistance to the individual being supervised but also acknowledges peers as providers of supervisory functions (Glickman, Calhoon, \& Roberts, 1993). It is a support mechanism for practicing professionals within which they can share clinical, organizational, developmental and emotional experiences with another professional in a secure, confidential environment in order to enhance knowledge and skills. This process will lead to an increased awareness of other concepts including accountability and reflective practice (Lytl, 2000).

Nondirective supervision is based on the assumption that an individual knows best what changes need to be made and has the ability to think and act on his or her own. The role of the supervisor is to assist in the process of thinking through the actions. It is appropriate when indi- 
viduals are functioning at high developmental levels and possess greater expertise, commitment or responsibility than the supervisor does. The purpose of nondirective supervision is to provide an active sounding board for thoughtful professionals (Glickman, Gordon, \& Ross-Gordon, 1998). Experts are most often achievement motivated individuals, who are highly responsible, self-motivated and are striving for excellence. As a result they work best in an environment in which they are trusted and given freedom. They value and need considerable dialogue with their supervisors to ensure that their goals are synchronized with those of the organization, but once set toward goals they require relatively little supervision (Brown, 1983).

\section{Conclusion}

The aim of supervision, in teaching and nursing should be reflective autonomous practice that is facilitated by nondirective supervision. Since many nurses are functioning at developmental levels or in situations in which self-direction is not feasible it means that the supervisor often must initially use collaborative, directive informational or in rare cases directive control behaviors. A matching of the developmental level of the nurse and the supervisory approach best allows for transition from novice through to expert stages of development ( Glickman, et al., 1998)

Clinical supervision facilitates the transition of nurses through various stages of career development. It is at the heart of successful professional nursing in that in enables staff to develop skills and attributes appropriate to the role as it is lived. By learning through supervision, nurses are assured of a mechanism that supports them in development and contributes to their continued future as professional (Barber \& Noman, 1987; Cooke, 1992).Clinical supervision should focus on the individual and unique learning needs, bridging the gap between expectation and realization, past and present experience and theory and practice (Holloway, 1994). If clinical supervision is used for the purposes of development of the practitioner it can facilitate effective transition from one stage of development to another as nurses move through their careers (Canham, 1998). It is also essential that clinical supervision is not an add-on, but an integral part of theory and practice of nursing in order to assure the development of competent and autonomous practitioners (Pollitt, 1988). Goldhammer (1969) describes clinical supervision as a collegial, team endeavor to support teachers in complementing and reinforcing each other for attaining a higher purpose in education. Clinical supervision is a process of helping teachers to become more aware of themselves, their students and the nature of teaching and learning. Issues of value, goodness and collective actions to rectify public education were at the heart of the work. This notion can also serve to improve the quality of nurses and nursing as it serves as an underpinning that allows for nurses to practice similarly as to what Goldhammer describes for teachers.
Clinical supervision using a developmental perspective has the potential to benefit patient care and nurses, both individually and as a profession. As nurses are expected to take on greater responsibility, appropriate supports such as supervision, that encourages exploration of practice, can be beneficial in professional development. Restructuring of the health care system has resulted in the demise of many of the clinical supports for practicing nurses. This has resulted in a situation which has left the nursing workforce underdeveloped, underutilized and demoralized. A reinvestment in a variety of strategies, including supervision, is needed to repair and realign the nursing workforce in Canada.

\section{Authors}

Glenn Donnelly RN, BScN, MN is a Doctoral Student, Faculty of Education, University of Regina \& Assistant Professor, College of Nursing, University of Saskatchewan., Saskatoon, SK.

Paulette Brooks, BEd., MEd., PhD is Assistant Professor, Faculty of Education, University of Regina, Regina, SK.

\section{References}

Bain, L. (1996). Preceptorship: A review of the literature. Journal of Advanced Nursing, 24, 104- 107.

Barber, E., \& Norman, B. (1987). An eclectic model of staff development: Supervision techniques to prepare nurses for a process approach-a social perspective. In P. Barber (Ed.), Mental handicap-facilitating holistic care . London: Hodder \& Stoughton.

Benner, P. (1982). From novice to expert. American Journal of Nursing. March, 402-407.

Benner, P. (1984). From novice to expert: Excellence and power in clinical nursing practice. Menlo Park, CA:

Addison-Wesley.

Benner, P., Tanner, C., \& Chesla, C. (1992). From beginner to expert: Gaining a differentiated clinical world in critical care nursing. Advances in Nursing Science 14(3), 13-28.

Benner, P., Tanner, C., \& Chesla, C. (1996). Expertise in nursing practice: Caring, clinical judgement and ethics. New York: Springer Publishing Co.

Bizek, K., \& Oermann, M. (1990). Study of educational experiences, support, and job satisfaction among critica! care preceptors. Heart \& Lung, 19, 439-444.

Brown, S. (1983). Administrative support. In A. Hamric \& J. Spross, (Eds.), The clinical nurse specialist in theory and practice. New York: Gune \& Stratton. 
Butcher, K. (1995). Taking notes. Nursing Times, 92, 33.

Butterworth, T., Carson, J. \& White, E. (1997). An evaluation of clinical supervision and mentorship in England and Scotland. Manchester: University of Manchester.

Butterworth, T., \& Faugier, J. (1992), Supervision for life. In T. Butterworth \& J. Faugier, (Eds), Clinical supervision and mentorship in nursing. (pp.230-239), London: Chapman. Hall.

Canham,J. (1998). Educational clinical supervision: Meeting the needs of specialist community practitioner students and professional practice. Nursing Education Today, 18, 394398.

Crain, C., \& Young T. (1990). How to meet the needs of beginning teachers. Tips for principals from NASSP. Reston, VA.: NASSP.

Cooke, P. (1992). Mental handicap nursing. In Butterworth T. \& Faugier J. (Eds.), Clinical supervision and mentorship in nursing. London: Chapman \& Hall.

Cutcliffe, J., Epling, M., \& Cassedy, P. (1998). Ethical dilemmas in clinical supervision. British Journal of Nursing $_{2} 7(16), 978-982$.

Cutcliffe, J., \& Proctor, B. (1998). An alternative training approach to clinical supervision. British Journal of Nursing, 6,725 .

Darling, L. (1985). Becoming a mentoring manager. Journal of Nursing Administration, 15(6)43-45.

Dreyfus, H., \& Dreyfus, S. (1980). Mind over machine. New York: MacMillan, The Free Press.

Dudley, M., \& Butterworth, T. (1994). The cost and some benefits of clinical supervision: an initial exploration. International Journal Psychiatric Nursing Research, 1, 34-40.

Garbett, R. (1995). Editor's. Nursing Times, 91(26), 28.

Glickamn, C, Calhoon, E., \& Roberts, J. (1993). Clinical supervision within the school as the center of inquiry. In $\mathrm{R}$. Anderson \& K. Snyder (Eds.), Clinical Supervision: Coaching for Higher Performance, Lancaster, PA: Technomic Pub.

Glickman, , P., Gordon, S., \& Ross-Gordon, J. (1998). Supervision of instruction: A developmental approach.

( $4^{\text {th }}$ Ed.) Needham Heights, MA.: Allyn \& Bacon.

Goldhammer, R. (1969). Clinical supervision: Special methods for the supervision of teachers . New York: Holt.
Gordon, S. (1991). How to help beginning teachers succeed. Virginia: ASCD.

Haipt, M. (1990). A guide for the voyage. Momentum, 21(4), 16-19.

Hallberg, I., \& Norberg, A. (1993). Strain among nurses and their emotional reactions during 1 year of systematic clinical supervision combined with the implementation of individualized care in dementia nursing. Journal of Advanced Nursing, 18, 1860-1875.

Hand, L.(1981). Nursing supervision.London: Prentice Hall.

Hawkins, P., \& Shohet, R. (1989). Supervision in the helping professions. Milton Keynes: Open University Press.

Houk, T. (1999). Supervising the beginning teacher. The Administrator, 29:2.

Holloway, E. (1994). A bridge of knowing: The scholarpractitioner supervision. Counseling Psychology Quarterly, 7(1), 13-15.

Lyth, G. (2000). Clinical supervision: A concept analysis. Journal of Advanced Nursing, 31(3), 722-729.

Oerman, M. (1990). Psychomotor skill development. Journal of Continuing Education in Nursing, 21(5), 202-205.

Pollitt, C. (1988). Consumerism and beyond (editorial). Public Administration, 65: 121-124.

Reilly, D., \& Oermann, M. (1990). Clinical teaching in nursing education ( $2^{\text {nd }}$ Ed.). New York: National League for Nursing.

Rocchiccioli, J. \& Tilbury, M. (1998).Clinical leadership in nursing. Toronto: W. B. Saunders Company.

Singleton, E. (1998). Supervision and delegation. In J. Rocchiccioli \& M. Tilbury (Eds.), Clinical leadership in nursing. Toronto: W. B. Saunders.

Stokes,L. (1998). Teaching in clinical settings. In D. Billings \& J. Halstead (Eds.), Teaching in Nursing: A guide for Faculty. Philadelphia: W. B. Saunders.

Wolsey, P., \& Leach, L. (1997). Clinical supervision: A hornets nest? Nursing Times 93(44), 24-27.

Yegdich, T. (1999). Lost in the crucible of supportive clinical supervision: Supervision is not therapy. Journal of Advanced Nursing, 29(5), 1265-1275. 